\title{
Johne's disease, Mycoplasma and BVD in Utah-Bulk Tank Milk Testing and Comparison to Previous Regional Prevalence and Individual Herd Results over Time
}

\author{
David J. Wilson*, Kerry A. Rood, Jennifer Bunnell, Chelsea Whitehouse, Todd M. Byrem and Gregory M. Goodell
}

Department of Animal, Dairy and Veterinary Sciences, Utah State University, USA

\begin{abstract}
Dairy herd-level prevalence of Mycobacterium avium subsp. paratuberculosis (MAP), causative agent of Johne's disease (JD), Mycoplasma spp., and Bovine Viral Diarrhea (BVD) virus were estimated in Utah and surrounding states and compared to previous surveillance results. Milk was collected at 3-4 day intervals on 5 dates (duplicate samples) from each bulk tank on participating farms, samples analyzed separately. One frozen sample was shipped to a laboratory for JD/MAP testing with ELISA and real-time PCR, the other paired sample was shipped to another laboratory for mycoplasma and BVD testing. Mycoplasma was cultured on modified Hayflick medium, standard methods; BVD testing was real-time, RT-PCR. 151/209 (72\%) eligible dairy farms participated. Farms detected positive (some had multiple diseases) were: 58 JD (38\%); 4 mycoplasma (3\%); 14 BVD (9\%). Sensitivity of testing was: $284 / 528$ milks $=54 \%$ for JD, $17 / 61=28 \%$ for mycoplasma (lower than previous reports), $41 / 117=35 \%$ for BVD . Of 67 herds positive for JD in 2009, 28 (42\%) remained positive, $14(21 \%)$ became test-negative, and $25(37 \%)$ were lost to follow up. Of 16 herds positive for mycoplasma in 2007, one (6\%) remained positive, $8(50 \%)$ became testnegative, and 7 (44\%) were lost to follow up. Bulk milk remains a practical way to screen dairy herds for presence of JD, mycoplasma and BVD, provided that repeated sampling is used. Mycoplasma-positive herds were more likely to become test-negative in bulk milk in subsequent years than were JD-positive herds. Prevalence of BVD was similar to but slightly lower than previously reported.
\end{abstract}

Keywords: Johne’s disease; mycoplasma; BVD; Milk; Dairy cattle

\section{Introduction}

Johne's disease (JD, paratuberculosis) is a chronic and important digestive tract disease of dairy cattle. Affected animals may exhibit no clinical signs, or signs including intermittent or chronic diarrhea, decreased milk production, weight loss, emaciation, and death. Increased risk of culling accompanies JD infection [1-6]. The etiologic agent is Mycobacterium avium subsp. paratuberculosis (MAP) [2].

Johne's disease is costly, but estimates of financial loss vary considerably from $\$ 250$ million to $\$ 1.5$ billion annually in the US, and may be underestimated $[4,6]$. Financial loss from JD has been estimated from $\$ 83$ to $\$ 380$ per infected cow depending on parity/age, $\$ 77$ in increased culling losses per cow for all cows within a herd, and $\$ 49$ to $\$ 200$ per cow for all cows within infected herds [5,7-9].

Estimates of the proportion of dairy herds infected with JD continue to vary between studies, regions, and countries, and it is acknowledged that definitive data is lacking. However, herd-level prevalence of JD is generally agreed to be increasing in North America, from approximately $10 \%$ to $30 \%$ of herds positive 25 years ago [10-12] to $38 \%$ to $74 \%$ of herds more recently, with most regional estimates at approximately $43 \%$ of dairy herds with JD [13-15].

Mycoplasma spp. are important bacterial pathogens for all ages of cattle, and can cause septicemia, pneumonia, arthritis, and death. Adult cows may also contract metritis, mastitis, or agalactia. The most common mycoplasma affecting cattle is $M$. bovis; infections can also be caused by $M$. californicum, $M$. arginini, $M$. canadense, $M$. bovigenitalium, and other Mycoplasma spp. [16-18]. Because standard bacterial culture methods do not isolate Mycoplasma spp., specialized laboratory methods are required for diagnosis [18-20].

Mycoplasma is a costly disease per case, but there are few published cost estimates. From mastitis and related sequelae alone, losses are estimated at $\$ 450$ per case, and mycoplasma is considered one of the most expensive dairy cattle diseases per affected animal [20,21].

Herd-level prevalence of mycoplasma has primarily been estimated by bulk tank milk sampling. Prevalence estimates have varied by regions in the U.S., from $2 \%$ in the Midwest to $9 \%$ of dairy herds in the West [22]. A recent survey in Québec detected 3\% of dairy herds with Mycoplasma spp. [23].

Bovine viral diarrhea (BVD) virus has been identified as economically important to livestock producers [9,24-27]. In a comprehensive review of the economic impact from BVD on dairy farms, it was estimated that BVD losses ranged between $\$ 10$ and $\$ 40$ dollars per calving in Denmark [27]. When direct production costs were examined in the Canadian dairy system (including milk loss, premature voluntary culling and reduced slaughter value, mortality loss, and abortion and reproductive loss), total annual costs were $\$ 2421$ in an infected herd of 50 cows [9].

The virus infects cattle through transient, usually self-eliminating, episodes of viral transmission within the herd or through animals persistently infected (PI) during gestation. If the virus infects the fetus in utero during the first few months of pregnancy while fetal immunity

*Corresponding author: David J. Wilson, Department of Animal, Dairy, and Veterinary Sciences, Utah State University, USA, Tel: 435-760-3731; Fax: 435-7972805; E-mail: David.Wilson@usu.edu

Received June 17, 2014; Accepted July 28, 2014; Published July 30, 2014

Citation: Wilson DJ, Rood KA, Bunnell J, Whitehouse C, Byrem TM (2014) Johne's disease, Mycoplasma and BVD in Utah-Bulk Tank Milk Testing and Comparison to Previous Regional Prevalence and Individual Herd Results over Time. J Veterinar Sci Technol 5: 182. doi:10.4172/2157-7579.1000182

Copyright: $\odot 2014$ Wilson DJ, et al. This is an open-access article distributed under the terms of the Creative Commons Attribution License, which permits unrestricted use, distribution, and reproduction in any medium, provided the original author and source are credited. 
Citation: Wilson DJ, Rood KA, Bunnell J, Whitehouse C, Byrem TM (2014) Johne's disease, Mycoplasma and BVD in Utah-Bulk Tank Milk Testing and Comparison to Previous Regional Prevalence and Individual Herd Results over Time. J Veterinar Sci Technol 5: 182. doi:10.4172/21577579.1000182

Page 2 of 7

is being developed, the virus is recognized as "self" and not eliminated nor does it elicit an immune response from the fetus which is therefore born PI. A PI animal sheds large amounts of virus and represents the most likely reason BVD circulates within herds [28].

BVD has been reported worldwide [29]. The prevalence for PI animals on U.S. dairy operations has been reported at $0.13 \%$ of cows, with $15 \%$ of herds having at least one PI animal [30]. Only a few studies have used PCR bulk milk sampling to determine herd prevalence of PI animals (percentage of herds with at least one PI), ranging from $15 \%$ in the U.S. [30] to $39 \%$ in Denmark [31].

Previous statewide surveillance projects in Utah detected JD in $39 \%$ and Mycoplasma spp. in 7\% of Utah dairy herds in 2009 and 2007, respectively [32,33]. Objectives of the study reported here included estimation of the dairy herd-level prevalence of JD, Mycoplasma spp., and BVD virus in Utah and the nearby Intermountain West using a repeated sampling scheme. Because JD and mycoplasma were previously surveyed in the same Utah dairy region, their herd-level prevalence and farm-specific test status were compared to the previous results.

\section{Materials and Methods}

Written permission of dairy producers was required in order to sample bulk tank milk for testing for JD, Mycoplasma spp., and BVD. Information and permission forms were distributed by email, surface mail and farm visits by milk buyer field personnel to dairy producers in Utah and some producers from surrounding states that sold milk to either of the 2 major milk buying companies in Utah.

\section{Collection and handling of bulk tank milk samples}

Milk was collected at 3-4 day intervals for a total of 5 sampling dates (duplicate samples each date from each bulk tank) on participating farms over approximately 15 days. Milk in the tank was agitated for at least 5 min before milk haulers collected 2 extra samples into sterile vials at the same time they collected their routine testing samples. All samples collected by the 2 milk buying companies were frozen at $-20^{\circ}$ $\mathrm{C}$ and remained frozen until analysis. Using portable $-20^{\circ} \mathrm{C}$ freezers, all samples were transported to the Utah Veterinary Diagnostic Laboratory from the collection locations and shipped frozen overnight by courier. One sample was sent to Antel BioSystems in Lansing, MI, and the other sample collected on the same day was sent to The Dairy Authority laboratory in Greeley, $\mathrm{CO}$ for testing.

\section{Testing for MAP in bulk tank milk samples}

At Antel BioSystems, 2 separate analyses were performed on each bulk tank sample as previously described $[32,34]$. Briefly, each bulk tank sample was analyzed for MAP-specific IgG antibody by ELISA and for presence of MAP organism by real-time PCR. For ELISA, $100 \mu \mathrm{L}$ of whole milk sample was tested using a commercially available, preabsorbed, antibody-capture ELISA (IDEXX Laboratories, Westbrook, ME, USA). The assay was performed as specified by the manufacturer with the following exceptions: A 1:1.5 dilution of milk sample into sample diluent instead of 1:2, $1 \mathrm{~h}$ incubation times for sample and conjugate steps instead of $0.5 \mathrm{~h}, 1: 67$ dilution of concentrated conjugate instead of 1:100, and $20 \mathrm{~min}$ for color development instead of 10 min prior to stopping the reaction with $0.5 \mathrm{M}$ sulfuric acid. Positive and negative controls supplied with the ELISA kit yielded optical density (OD) values $(420 \mathrm{~nm}$ ) between 2.3 and 3.0, and less than 0.10 , respectively. Scores for ELISA were calculated by subtracting negative control values from each sample value and compared to a statistically optimized cut-off of 0.1 [34,35]. The cut-off of 0.1 OD, where ELISA scores above 0.1 are considered positive for JD, yields a test sensitivity and specificity of $52 \%$ and $94 \%$, respectively, when compared to environmental fecal analysis as the "gold standard" for MAP infection in dairy herds $[34,35]$.

For real-time PCR analysis for presence of MAP in milk, $100 \mathrm{uL}$ of Tween- 20 was added to $50 \mathrm{~mL}$ of bulk milk processed by centrifugation $(2500 \mathrm{x} \mathrm{g})$ and total DNA extracted from the pellet using a DNeasy ${ }^{\mathrm{TM}}$ spin kit (Qiagen Corporation, Valencia, CA, USA). Real-time PCR was performed in a $50 \mu \mathrm{L}$ reaction volume, containing $25 \mu \mathrm{L}$ TaqMan Universal Master Mix; $0.9 \mu \mathrm{M}$ IS900 Primer; $0.9 \mu \mathrm{M}$ internal control primer; $0.1 \mu \mathrm{M}$ IS900 FAM labeled probe; $0.1 \mu \mathrm{M}$ internal control VIC labeled probe; $0.25 \mathrm{ng}$ internal control plasmid and $10 \mu \mathrm{L}$ of sample or control. The real-time PCR reaction conditions were as follows: 1 cycle of $95^{\circ} \mathrm{C}$ for 10 minutes; and 45 cycles of $95^{\circ} \mathrm{C}$ for 15 seconds, $60^{\circ} \mathrm{C}$ for 1 minute. Cycle threshold values below 41 are considered positive for the presence of MAP. Sensitivity and specificity are $40 \%$ and $94 \%$, respectively, when compared to environmental fecal analysis for MAP infection in dairy herds [34,35].

\section{Testing for mycoplasma in bulk tank milk samples}

Milk was cultured for mycoplasma on modified Hayflick medium, $37^{\circ} \mathrm{C}$ incubation in a $5 \% \mathrm{CO}_{2}$ incubator. Plates were read at 3,7 and 10 $\mathrm{d}$ post- inoculation before being declared negative if no mycoplasma colonies were detected by that time, as described previously [33].

\section{Testing for BVD in bulk tank milk samples}

Milk samples were screened for BVD virus using a VetMAX ${ }^{\mathrm{m}}$-Gold BVDV Detection Kit (Applied Biosystems, Carlsbad, CA, USA) realtime reverse transcription PCR kit as per manufacturer's instructions as reported previously [36]. Before detection samples were extracted using the MagMAX ${ }^{\text {si }}$ Total Nucleic Acid Isolation Kit (Applied Biosystems, Carlsbad, CA, USA). This kit employs mechanical disruption of samples with zirconia beads in a guanidinium thiocyanate-based solution that rapidly releases nucleic acid (NA) while simultaneously inactivating nucleases in the sample matrix $[37,38]$. Samples are then diluted with isopropanol, and paramagnetic beads with an NA binding surface are added to the sample. The beads/NA are immobilized on magnets and washed to remove proteins and other contaminants. A second wash solution is used to remove residual binding solution, and finally NA is eluted in a small volume of low-salt buffer. For amplification and detection of BVD 17 uL RT-PCR master mix were dispensed into each well of a PCR plate followed by $8 \mathrm{uL}$ negative control (nuclease-free water), positive control, extraction control (mock-purified PBS), or test sample (milk) for a total volume in each well of $25 \mathrm{uL}$. The wells were then sealed with flat caps.

Amplification was performed using a Bio-Rad IQ5 Multicolor RealTime PCR Detection System. Two fluorescent dyes were used for RTPCR with different targets; FAM for BVD RNA, and Cal Fluor Orange 560 dye for the Xeno RNA control (included in each sample as an internal control to ensure proper isolation).

\section{Case definitions and statistical methods}

The definition of "true positive" for JD, mycoplasma or BVD in a herd was the finding of at least 1 positive test result for that disease. Therefore by definition specificity (avoidance of false positives) was $100 \%$; no positive results were defined as "false positive". Specificity for JD, mycoplasma, and BVD milk testing was previously reported as nearly $100 \%$; false positive results are uncommon [33-35,39].

Test sensitivity (proportion of samples from true positive herds that 
Citation: Wilson DJ, Rood KA, Bunnell J, Whitehouse C, Byrem TM (2014) Johne's disease, Mycoplasma and BVD in Utah-Bulk Tank Milk Testing and Comparison to Previous Regional Prevalence and Individual Herd Results over Time. J Veterinar Sci Technol 5: 182. doi:10.4172/21577579.1000182

tested positive; avoidance of false negatives) was calculated for detection of each of the 3 diseases, analyzed separately. Sensitivity was defined as the total number of positive test results for a given disease divided by the total number of tests (ELISA and real-time PCR defined as one combined test for JD; there were single tests performed on each sample for mycoplasma and BVD) performed on all bulk milk samples from the herds detected at least once as positive for that disease. For example, if there were 284 JD-positive bulk tank samples among a total of 528 bulk tank samples from all farms that tested positive for JD, sensitivity $=284 / 528=54 \%$ for a single bulk tank sample test to detect JD.

Using sequential probability, the probability that any particular herd for which all tests were negative was a "true negative" for each disease, analyzed separately, was calculated. First, the probability of false-negative status was calculated as $(1 \text { - sensitivity })^{\mathrm{n}}$ where $\mathrm{n}=$ number of bulk tank milk tests performed. For example, if sensitivity was $54 \%$, and one bulk tank was sampled and tested 5 times for JD with all tests negative, the probability of false-negative status for the disease would be $(1-0.54)^{5}=(0.46)^{5}=0.02$. Then the probability of true-negative for JD status would be calculated as $(1-0.02)=98 \%$. Farms with $>5$ total bulk tank tests because they had more than one tank would have a higher probability of being true-negative.

\section{Confidentiality of results}

Farms were coded by number for anonymity by the 2 milk buyers; the investigators did not know the dairy producers' identities. Owners of herds positive for any of the 3 diseases were contacted through the milk buyer field personnel using their number code; if they confirmed that they would allow their identification to be revealed, their identities were revealed to the investigators. This allowed tracking of individual herds over time, and contact for a follow up program including farm visits.

\section{Results}

\section{Sample collection}

Signed forms authorizing milk sample collection and testing were returned by $151 / 209$ (72\%) of the dairy producers in the study area of Utah and adjacent areas of the Intermountain West. Bulk tank milk samples ( $\mathrm{n}=1,822$, 911 pairs) were collected from all 179 bulk tanks on the 151 participating dairy farms, sampled 3-4 days apart. The number of bulk tank milk samples collected per farm ranged from 4 (8 farms) to 38 ( 1 farm). All samples were frozen as described earlier, and arrived frozen at the testing laboratories.

\section{Herds testing positive for at least one disease}

There were 68 herds ( $45 \%$ ) that tested positive for one or more of the 3 diseases; 61 herds were positive for one of the diseases, 6 herds were positive for 2 of the diseases, and one herd was positive for all 3 diseases. The remaining 83 herds (55\%) tested negative for JD, mycoplasma and BVD. All combinations of proportion of bulk tank milk samples testing positive for each disease, number of samples collected, and the number of farms with each combination of results are shown in Table 1. For example, 5 farms had 10/10 samples positive for JD, and 3 farms had 1/5 samples positive for BVD (Table 1).

\section{Herd-level prevalence of JD}

Johne's disease was detected in bulk tank milk by at least one test from 58/151 dairy herds (38\%) in Utah and adjacent study areas (Table 1). Some of these herds were also positive for mycoplasma or BVD, and one had all 3 diseases (more details regarding multiple infections will
Table 1: Bulk tank test results for presence of Johne's disease (JD), Mycoplasma spp. and Bovine Viral Diarrhea (BVD) in 151 dairy herds with 179 bulk tanks in Utah and parts of surrounding states. All combinations of proportion of positive samples and number of bulk tank samples collected are shown for each disease.

\begin{tabular}{|c|c|c|c|}
\hline \multicolumn{4}{|c|}{ Disease } \\
\hline JD & Mycoplasma & & BVD \\
\hline $\begin{array}{l}\text { Pos./No. tank } \\
\text { samples }(n)^{*}\end{array}$ & $\begin{array}{l}\text { Pos./No. tank } \\
\text { samples }(n)^{*}\end{array}$ & Pos./N & ank samples $(n)^{*}$ \\
\hline $15 / 15(1)$ & $4 / 10(1)$ & & $9 / 9(1)$ \\
\hline $12 / 12(1)$ & $6 / 18(1)$ & & $5 / 5(2)$ \\
\hline $11 / 11(1)$ & $3 / 11(1)$ & & $7 / 9$ (1) \\
\hline $10 / 10(5)$ & $4 / 22(1)$ & & H/11 (1) \\
\hline $9 / 9(1)$ & & & $1 / 4(1)$ \\
\hline $5 / 5(9)$ & & & $1 / 5(3)$ \\
\hline $4 / 4(1)$ & & & 1/6 (3) \\
\hline $5 / 6(2)$ & & & $3 / 25(1)$ \\
\hline $10 / 12(1)$ & & & //16 (1) \\
\hline \multicolumn{4}{|l|}{$8 / 10(1)$} \\
\hline \multicolumn{4}{|l|}{$4 / 5(2)$} \\
\hline \multicolumn{4}{|l|}{$7 / 10(1)$} \\
\hline \multicolumn{4}{|l|}{$16 / 25(1)$} \\
\hline \multicolumn{4}{|l|}{$3 / 5(2)$} \\
\hline \multicolumn{4}{|l|}{$5 / 9(1)$} \\
\hline \multicolumn{4}{|l|}{$12 / 22(1)$} \\
\hline \multicolumn{4}{|l|}{$15 / 30(1)$} \\
\hline \multicolumn{4}{|l|}{$2 / 4(1)$} \\
\hline \multicolumn{4}{|l|}{$2 / 5(4)$} \\
\hline \multicolumn{4}{|l|}{$2 / 8(1)$} \\
\hline \multicolumn{4}{|l|}{$2 / 6(2)$} \\
\hline \multicolumn{4}{|l|}{$2 / 10(2)$} \\
\hline \multicolumn{4}{|l|}{$1 / 5(7)$} \\
\hline \multicolumn{4}{|l|}{$1 / 6(1)$} \\
\hline \multicolumn{4}{|l|}{$6 / 38(1)$} \\
\hline \multicolumn{4}{|l|}{$1 / 9(1)$} \\
\hline \multicolumn{4}{|l|}{$1 / 10(3)$} \\
\hline \multicolumn{4}{|l|}{$1 / 12(1)$} \\
\hline \multicolumn{4}{|l|}{$1 / 17$ (1) } \\
\hline \multicolumn{4}{|l|}{$1 / 21(1)$} \\
\hline $58(38 \%)$ & $4(3 \%)$ & $14(9 \%)$ & Total positive herds ${ }^{\dagger}$ \\
\hline $93(62 \%)$ & $147(97 \%)$ & $137(91 \%)$ & Total negative herds ${ }^{\ddagger}$ \\
\hline
\end{tabular}

* Number of samples that tested positive of the total number of tank samples collected from herds detected with that disease. $(n)=$ the number of herds with that combination of test results

† Total number and (percent) of herds positive for each disease

₹ Total number and (percent) of herds test-negative for each disease

follow). The proportion of bulk tank samples testing JD-positive among the positive herds ranged from $100 \%$ ( 19 herds) to $5 \%$ (one herd). The median proportion of bulk tanks testing JD-positive among all positive herds was $3 / 5$ (60\%) (Table 1). Variability in shedding of MAP was evident in the case of the farm with the largest number of bulk tank samples collected (38 samples). That farm had 3 bulk tanks, all with milk picked up twice every day, sometimes 3 times within $24 \mathrm{~h}$. All 6 
Citation: Wilson DJ, Rood KA, Bunnell J, Whitehouse C, Byrem TM (2014) Johne's disease, Mycoplasma and BVD in Utah-Bulk Tank Milk Testing and Comparison to Previous Regional Prevalence and Individual Herd Results over Time. J Veterinar Sci Technol 5: 182. doi:10.4172/21577579.1000182

Page 4 of 7

JD-positive tank results - from 2 of the 3 tanks only - were JD-negative when collected approximately 12 hours earlier or later on the same day.

\section{Herd-level prevalence of mycoplasma}

Mycoplasma was detected in bulk tank milk by at least one test from $4 / 151$ herds (3\%) (Table 1). Two of the 4 herds were JD-positive also, and one had all 3 diseases including BVD. The proportion of their bulk tanks testing mycoplasma-positive were similar for all 4 herds: 6/18 (33\%), 4/22 (18\%), 4/10 (40\%), 3/11 (27\%). All of the farms that tested positive for mycoplasma had more than one bulk tank, and most or all tanks on a given farm were positive on some sample dates, while all tanks on the same farm were negative on other sample dates.

\section{Herd-level prevalence of BVD}

At least one test of bulk tank milk detected BVD from 14/151 herds (9\%). Four of the 14 herds were JD-positive also, and another herd was positive for mycoplasma and JD as well (Table 1). The proportion of their bulk tanks testing BVD-positive ranged from 100\% (3 herds) to $6 \%$ (one herd). The median proportion of their bulk tanks testing BVDpositive was $1 / 5$ (Table 1 ).

\section{Johne's disease prevalence changes over time}

Using the same tests as in the current study, the same dairy region was surveyed previously for JD in 2009 , with $67 / 170$ (39\%) of dairy herds detected with JD [32]. However, the previous study collected 2 samples from every bulk tank while the current study collected 5 samples per tank. Of the 67 herds positive for JD in 2009, 28 (42\%) remained positive in $2013,14(21 \%)$ became test-negative, $4(6 \%)$ did not participate, and $21(31 \%)$ exited the industry or changed to a nonparticipating buyer by 2013 .

Of the 103 herds that were JD test-negative in 2009, 65 were retested 4 years later, and 13 (20\%) became newly test-positive. There were 44 herds that did not participate in the previous surveillance project for JD (43 of the herds existed in 2009, one herd was assembled after 2009) and were therefore tested for JD for the first time in 2013; 17 (39\%) tested JD-positive - the herd assembled after 2009, and 16 that did not participate in the earlier surveillance project. Therefore the apparent herd-level new infection rate for JD was $20 \%$ over a 4 year period for herds tested negative previously and the JD prevalence was $39 \%$ for herds not tested before. The overall herd-level prevalence of JD in Utah and surrounding areas remained essentially unchanged over 4 years, $39 \%$ to $38 \%$.

\section{Mycoplasma prevalence changes over time}

The same dairy region was previously surveyed for mycoplasma in 2007, using the same test methods and sampling scheme as the present study, with 16/222 (7\%) of dairy herds detected with mycoplasma [33]. Of the 16 herds positive for mycoplasma in 2007, one (6\%) remained positive in 2013 (the herd with all 3 diseases), 8 (50\%) became testnegative ( 3 of those were already known to be test-negative by 2008 by the authors working closely with the owners, and they remained negative in 2013), 2 (13\%) did not participate, and 5 (31\%) exited the industry or changed to a non-participating buyer by 2013 .

Of the 206 herds that were mycoplasma test-negative in 2007, 116 were re-tested 6 years later, and one (1\%) became newly test-positive. There were 26 herds that did not participate in the previous surveillance project for mycoplasma ( 25 of the herds existed in 2007 , one herd was assembled after 2007) and were therefore tested for mycoplasma for the first time in 2013; 2 (8\%) tested mycoplasma-positive - the herd assembled after 2007, and one that did not participate in the earlier surveillance project. Therefore the apparent herd-level new infection rate for mycoplasma mastitis was $1 \%$ over a 6 year period for herds tested negative previously and the mycoplasma prevalence was $8 \%$ for herds not tested before. The overall herd-level prevalence of mycoplasma in Utah and surrounding areas decreased from 7\% to 3\% over 6 years.

\section{Bulk tank test sensitivity}

Test sensitivity for JD detection was calculated by dividing the total number of JD-positive bulk tank results (whether by either the ELISA, real-time PCR, or both tests) by the total number of bulk tank milk samples tested from the JD-positive farms. There were 284 JDpositive bulk tank samples among the 528 bulk tank samples from the 58 positive farms; therefore $284 / 528=54 \%$ sensitivity of a single bulk tank sample test for detection of JD.

Calculated in the same way, sensitivity of testing (proportion of samples from true positive farms that tested positive) was: $17 / 61=28 \%$ for mycoplasma, $41 / 117=35 \%$ for BVD.

\section{Estimates of true-negative status for $100 \%$ test-negative herds}

Because the bulk tank sample test sensitivity for detection of JD was $54 \%$, the probability of false-negative results on a single negative tank test was $(1-0.54)=0.46$. The probability of true-negative JD status depending on the number of bulk tank milk samples tested from any given farm was calculated as described earlier. For example, for farms with one bulk tank, 5 samples collected 3-4 days apart, with all 5 samples testing negative (by both ELISA and real-time PCR) for JD, the true-negative probability was $\left[1-(0.46)^{5}\right]=(1-0.02)=98 \%$. For farms with more than one bulk tank, with all results negative for JD, the truenegative probability was greater, $\left[1-(0.46)^{\mathrm{n}}\right]$ where $\mathrm{n}=$ the number of samples that tested negative for JD.

For mycoplasma detection, with test sensitivity of $28 \%$, the probability of false-negative results on a single negative tank test was (1 $-0.28)=0.72$. For farms with one bulk tank, with all 5 samples testing negative for mycoplasma, the true-negative probability was $\left[1-(0.72)^{5}\right]$ $=(1-0.19)=81 \%$.

For BVD detection, with test sensitivity of $35 \%$, the probability of false-negative results on a single negative tank test was $(1-0.35)=0.65$. For farms with one bulk tank, with all 5 samples testing negative for BVD, the true-negative probability was $\left[1-(0.65)^{5}\right]=(1-0.12)=88 \%$. As explained for JD above, for mycoplasma and BVD it was also true that for farms with more than one bulk tank, with all results negative for either disease, the true-negative probability was greater.

\section{Discussion}

Approximately $40 \%$ of dairy herds in Utah and parts of surrounding states tested positive for JD, the same as 4 years earlier. These results are similar to other recent estimates of herd-level prevalence of JD in the US, supporting the speculation that the proportion of herds infected has increased over the last 15 to 20 years [13,14]. However, it is encouraging that JD prevalence apparently did not increase from 2009 to 2013, suggesting that the herd-level new infection rate may be slowing. The predominant characteristic of prevalence estimates for JD in North America is that data is lacking; there is little testing for paratuberculosis carried out in dairy herds [40]. The lack of data regarding JD prevalence also exists in Europe. Recently a review of the European literature concluded that "prevalences of MAP would have to be guesstimates based on available data" and "there is a continuing need for well-designed studies of the prevalence of MAP infections" [41]. 
Compared to 4 years earlier, two-thirds of previously JD-positive herds that were retested remained positive. This agrees with previous experience and reports that JD is difficult to eliminate from dairy herds. The most surprising thing about these results was that onethird became test-negative, a higher proportion than expected. Despite the mathematical calculations and the accepted use of sequential probability in repeat testing, the authors suspect that most of those herds probably still have some cows infected with JD, possibly in small numbers of cows. All of the herds with which the authors worked closely following the previous surveillance project reduced withinherd prevalence of JD, but none achieved complete elimination based on individual cow testing. Of the herds tested negative previously, $20 \%$ became test-positive for JD 4 years later, but JD prevalence was $39 \%$ for herds that had not been tested before, similar to the prevalence found in herds of unknown status in the first surveillance project.

Herds testing positive for mycoplasma in Utah decreased from $7 \%$ in 2007 to $3 \%$ in the present study. This was in association with a farm-specific outreach and follow up program, and also large group meeting and dairy press presentations in Utah and the Intermountain West regarding mycoplasma testing and culling. Proportion of dairy herds testing positive in milk for mycoplasma had been observed to be increasing for many years $[18,20,42]$, but may be decreasing recently at least in some regions, as producers and veterinarians are not only more familiar with the disease, but more are utilizing screening and monitoring programs for the disease.

A potential limitation of this study is that Mycoplasma spp. were not differentiated. This is the way that most testing for mycoplasma is done in the dairy industry because speciation is expensive and has little demonstrated benefit. In previous studies, most mycoplasma detected in milk of dairy cows has been M. bovis, or other species pathogenic to dairy cattle [18,42].

Test sensitivity of a single bulk tank milk culture for mycoplasma was lower than previously reported, $28 \%$ compared with earlier sensitivities of approximately 50\% [33,42]. All mycoplasma-positive herds were positive in most tanks only on certain sample dates, and completely negative on other sample dates, reinforcing the concept that mycoplasma is shed intermittently into milk and repeated sampling increases the probability of detecting truly infected herds [33].

Compared to 6 years earlier, the vast majority of previously mycoplasma-positive herds that were retested, nearly $90 \%$, became test-negative (the only herd remaining positive for mycoplasma was the only herd that also had JD and BVD). The remaining positive herd's management has told the authors for years that they have no control program for the 3 diseases, including any testing, culling or herd replacement screening. This high proportion of mycoplasma-infected herds becoming test-negative agrees with the experience of one of the authors (DW). Mycoplasma is an important disease, and leaving it in a herd long-term has always been part of the history of the worst clinical outbreaks causing marked death, culling and financial losses. Therefore "living with it" is not a recommended strategy; testing and culling positive cows is recommended, especially due to the contagious nature of mycoplasma infections. Three of the 8 previously positive farms that tested mycoplasma-negative in the current study had worked closely with the authors and became test-negative within one year after the previous study, and two others were actively testing for and culling positive cows then. Nevertheless, it has been observed that mycoplasmapositive herds often become completely test-negative in the milk of the adult herd within 18 - 24 months following initial detection even without intense elimination efforts. Of $>100$ herds tested negative previously, only one became test-positive for mycoplasma 6 years later, but mycoplasma prevalence was $8 \%$ for herds that had not been tested before, similar to the prevalence found in herds of unknown status in the first surveillance project.

The overall detection percentage of BVD-positive farms, $9 \%$, was similar to that reported following a national survey in 2007, which found $8 \%$ of western dairy farms BVD-positive [43]. This was lower than an earlier report of $12 \%$ herd-level BVD prevalence on New York dairy farms [44]. One limitation of using bulk tank samples to detect BVD is the possibility that all PI animals in a herd may not be lactating when samples are collected.

Five farms had multiple bulk tank samples positive for BVD. We are confident that farms with multiple BVD-positive test results were truly infected with BVD (likely the result of one or more PI animals present in the herd) because of previously reported high sensitivity and specificity using RT-PCR on bulk tank samples to detect PI animals $[44,45]$.

Two known reasons may explain why some farms only had a single sample detected as BVD-positive. Persistently infected animals may have either been removed from or added to the lactating herd during the sampling period. Also, Drew et al. [45] suggested that as the total number of cows' milk in a tank increased, the likelihood of BVD detection decreased because of dilution. Renshaw et al. [44] suggested that 1:600 ratio of PI's to total number of milked animals was the upper limit of BVD detection because of dilution. The number of cows milked into each bulk tank was not determined in this project. Many dairy farms had multiple tanks and the number of cows milked into a particular tank was not consistent depending on pickup date and time.

Testing of dairy herds for Johne's disease, mycoplasma and BVD has been increasingly adopted in recent years, but such testing is still underutilized, especially in screening dispersing herds for possible purchase as replacements in the dairy industry. Given the test sensitivities of a single bulk tank milk culture for detection of the 3 diseases reported here, a minimum of 4 but preferably at least 5 bulk tank samples from each tank on a farm should be tested for screening its herd. If all 5 samples are test-negative, there is a high statistical probability that the herd is truly negative for Johne's disease, mycoplasma and BVD. Nevertheless, if the proportion of cows infected is low, and/or most infected cows happen to be in a hospital string such that their milk is discarded from shipment, truly positive herds may still not be detected by bulk tank cultures. Any positive test result indicates high likelihood that the herd is infected; these are highly specific tests. However, if a dairy producer is reluctant to progress to individual cow testing for any of the diseases after one positive bulk tank result, additional bulk tank tests could be performed until there is another positive result. An ongoing repeated testing strategy on bulk tank milk such as collecting monthly samples is a convenient and practical method to screen for the presence of Johne's disease, mycoplasma and BVD in dairy herds.

\section{Acknowledgements}

This work was funded by grants from Utah State University, Federal Formula Animal Health Funds, Utah Agricultural Experiment Station, and Utah State University Extension Grants. We appreciate the cooperation of the owners of the participating dairy farms and the milk buyer personnel who recruited the participants and collected the milk samples.

\section{References}

1. Wilson DJ, Rossiter C, Han HR, Sears PM (1993) Association of Mycobacterium paratuberculosis infection with reduced mastitis, but with decreased milk production and increased cull rate in clinically normal dairy cows. See commen in PubMed Commons below Am J Vet Res 54 1851-1857. 
Citation: Wilson DJ, Rood KA, Bunnell J, Whitehouse C, Byrem TM (2014) Johne's disease, Mycoplasma and BVD in Utah-Bulk Tank Milk Testing and Comparison to Previous Regional Prevalence and Individual Herd Results over Time. J Veterinar Sci Technol 5: 182. doi:10.4172/21577579.1000182

Page 6 of 7

2. Stabel JR (1998) Johne's disease: a hidden threat. See comment in PubMed Commons below J Dairy Sci 81: 283-288.

3. Tiwari A, VanLeeuwen JA, Dohoo IR, Stryhn H, Keefe GP, et al. (2005) Effects of seropositivity for bovine leukemia virus, bovine viral diarrhoea virus, Mycobacterium avium subspecies paratuberculosis, and Neospora caninum on culling in dairy cattle in four Canadian provinces. See comment in PubMed Commons below Vet Microbiol 109: 147-158

4. Clark DL Jr, Koziczkowski JJ, Radcliff RP, Carlson RA, Ellingson JL (2008) Detection of Mycobacterium avium subspecies paratuberculosis: comparing fecal culture versus serum enzyme-linked immunosorbent assay and direct fecal polymerase chain reaction. See comment in PubMed Commons below $J$ Dairy Sci 91: 2620-2627.

5. Tiwari A, VanLeeuwen JA, Dohoo IR, Keefe GP, Weersink A (2008) Estimate of the direct production losses in Canadian dairy herds with subclinical Mycobacterium avium subspecies paratuberculosis infection. See comment in PubMed Commons below Can Vet J 49: 569-576.

6. Salem M, Heydel C, El-Sayed A, Ahmed SA, Zschöck M, et al. (2013) Mycobacterium avium subspecies paratuberculosis: an insidious problem for the ruminant industry. See comment in PubMed Commons below Trop Anim Health Prod 45: 351-366.

7. Wilson DJ, Rossiter CM, Han HR, Sears PM (1995) Financial effects of Mycobacterium paratuberculosis on mastitis, milk production and cull rate in clinically normal cows. Agri Pract 16:12-18.

8. Ott SL, Wells SJ, Wagner BA (1999) Herd-level economic losses associated with Johne's disease on US dairy operations. See comment in PubMed Commons below Prev Vet Med 40: 179-192.

9. Chi J, VanLeeuwen JA, Weersink A, Keefe GP (2002) Direct production losses and treatment costs from bovine viral diarrhoea virus, bovine leukosis virus, Mycobacterium avium subspecies paratuberculosis, and Neospora caninum See comment in PubMed Commons below Prev Vet Med 55: 137-153.

10. Merkal RS, Whipple DL, Sacks JM, Snyder GR (1987) Prevalence of Mycobacterium paratuberculosis in ileocecal lymph nodes of cattle culled in the United States. See comment in PubMed Commons below J Am Vet Med Assoc 190: 676-680.

11. Collins MT, Sockett DC, Goodger WJ, Conrad TA, Thomas CB, et al. (1994) Herd prevalence and geographic distribution of, and risk factors for, bovine paratuberculosis in Wisconsin. See comment in PubMed Commons below J Am Vet Med Assoc 204: 636-641.

12. Sockett DC (1996) Johne's disease eradication and control: Regulatory implications: The Veterinary clinics of North America. Food animal practice. W.B. Saunders Company, Philadelphia, London, Toronto, 12: 431-440

13. Tiwari A, VanLeeuwen JA, McKenna SL, Keefe GP, Barkema HW (2006) Johne's disease in Canada Part I: clinical symptoms, pathophysiology, diagnosis, and prevalence in dairy herds. See comment in PubMed Commons below Can Vet J 47: 874-882.

14. Tavornpanich S, Johnson WO, Anderson RJ, Gardner IA (2008) Herd characteristics and management practices associated with seroprevalence of Mycobacterium avium subsp paratuberculosis infection in dairy herds. See comment in PubMed Commons below Am J Vet Res 69: 904-911.

15. Sorge US, Lissemore K, Godkin A, Jansen J, Hendrick S, et al. (2011) Changes in management practices and apparent prevalence on Canadian dairy farms participating in a voluntary risk assessment-based Johne's disease control program. J Dairy Sci 94: 5227-5237.

16. Byrne WJ, McCormack R, Brice N, Egan J, Markey B, et al. (2001) Isolation of Mycoplasma bovis from bovine clinical samples in the Republic of Ireland. See comment in PubMed Commons below Vet Rec 148: 331-333.

17. Pfützner H, Sachse K (1996) Mycoplasma bovis as an agent of mastitis pneumonia, arthritis and genital disorders in cattle. See comment in PubMed Commons below Rev Sci Tech 15: 1477-1494.

18. González RN, Wilson DJ (1997) Where are we on mycoplasmal mastitis? Proceedings of the 89th Annual Conference for Veterinarians, pp 191-195.

19. González RN, Sears PM, Wilson DJ, Mohammed HO (1995) Epidemiology of mycoplasmal bovine mastitis in the state of New York, U.S.A. Proceedings of the Third International Dairy Federation Mastitis Seminar:68.

20. Maunsell FP, Woolums AR, Francoz D, Rosenbusch RF, Step DL, et al. (2011) Mycoplasma bovis infections in cattle. See comment in PubMed Commons below J Vet Intern Med 25: 772-783.
21. Wilson DJ, Gonzalez RN, Das HH (1997) Bovine mastitis pathogens in New York and Pennsylvania: prevalence and effects on somatic cell count and milk production. See comment in PubMed Commons below J Dairy Sci 80: 25922598.

22. USDA APHIS (2003) Mycoplasma in Bulk Tank Milk on U.S. Dairies. USDA APHIS Veterinary Services Info Sheet.

23. Francoz D, Bergeron L, Nadeau M, Beauchamp G (2012) Prevalence of contagious mastitis pathogens in bulk tank milk in Québec. See comment in PubMed Commons below Can Vet J 53: 1071-1078.

24. Dubovi EJ (1994) Impact of bovine viral diarrhea virus on reproductive performance in cattle: The Veterinary clinics of North America. Food animal practice. 10: 503-514.

25. Hessman BE, Fulton RW, Sjeklocha DB, Murphy TA, Ridpath JF, et al (2009) Evaluation of economic effects and the health and performance of the general cattle population after exposure to cattle persistently infected with bovine viral diarrhea virus in a starter feedlot. Am J Vet Res 70: 73-85.

26. Houe H (1999) Epidemiological features and economical importance of bovine virus diarrhoea virus (BVDV) infections. See comment in PubMed Commons below Vet Microbiol 64: 89-107.

27. Houe $H$ (2003) Economic impact of BVDV infection in dairies. See comment in PubMed Commons below Biologicals 31: 137-143.

28. Lindberg A, Houe $H$ (2005) Characteristics in the epidemiology of bovine viral diarrhea virus (BVDV) of relevance to control. See comment in PubMed Commons below Prev Vet Med 72: 55-73.

29. Houe H (1995) Epidemiology of bovine viral diarrhea virus. See comment in PubMed Commons below Vet Clin North Am Food Anim Pract 11: 521-547.

30. Houe H, Baker JC, Maes RK, Wuryastuti H, Wasito R, et al. (1995) Prevalence of cattle persistently infected with bovine viral diarrhea virus in 20 dairy herds in two counties in central Michigan and comparison of prevalence of antibodypositive cattle among herds with different infection and vaccination status. See comment in PubMed Commons below J Vet Diagn Invest 7: 321-326.

31. Bitsch V, Rønsholt L (1995) Control of bovine viral diarrhea virus infection without application of vaccines: The Veterinary clinics of North America. Food animal practice. (Volume 11), W.B. Saunders Company, Philadelphia, London, Toronto.

32. Wilson DJ, Rood K, Biswas P, Byrem TM (2010) Herd-level prevalence of Johne's disease in Utah and adjacent areas of the intermountain west as detected by a bulk-tank milk surveillance project. See comment in PubMed Commons below J Dairy Sci 93: 5792-5797.

33. Wilson DJ, Goodell G, Justice-Allen A, Smith ST (2009) Herd-level prevalence of Mycoplasma spp mastitis and characteristics of infected dairy herds in Utah as determined by a statewide survey. See comment in PubMed Commons below J Am Vet Med Assoc 235: 749-754.

34. Biswas PW, Foshaug H, Donohue H, Lombard J, Byrem T (2008) Bulk milk testing for Johne's disease detection at the farm level. Proceedings of the Fourth Annual Conference of the Johne's Disease Integrated Program (JDIP).

35. Lombard JE, Wagner BA, Smith RL, McCluskey BJ, Harris BN, et al. (2006) Evaluation of environmental sampling and culture to determine Mycobacterium avium subspecies paratuberculosis distribution and herd infection status on US dairy operations. See comment in PubMed Commons below J Dairy Sci 89 : 4163-4171.

36. Bhudevi B, Weinstock D (2001) Fluorogenic RT-PCR assay (TaqMan) for detection and classification of bovine viral diarrhea virus. See comment in PubMed Commons below Vet Microbiol 83: 1-10.

37. Chirgwin JM, Przybyla AE, MacDonald RJ, Rutter WJ (1979) Isolation of biologically active ribonucleic acid from sources enriched in ribonuclease. See comment in PubMed Commons below Biochemistry 18: 5294-5299.

38. Chomczynski P, Sacchi N (1987) Single-step method of RNA isolation by acid guanidinium thiocyanate-phenol-chloroform extraction. See comment in PubMed Commons below Anal Biochem 162: 156-159.

39. Kim SG, Dubovi EJ (2003) A novel simple one-step single-tube RT-duplex PCR method with an internal control for detection of bovine viral diarrhoea virus in bulk milk, blood, and follicular fluid samples. See comment in PubMed Commons below Biologicals 31: 103-106.

40. Espejo LA, Godden S, Hartmann WL, Wells SJ (2012) Reduction in incidence of 
Citation: Wilson DJ, Rood KA, Bunnell J, Whitehouse C, Byrem TM (2014) Johne's disease, Mycoplasma and BVD in Utah-Bulk Tank Milk Testing and Comparison to Previous Regional Prevalence and Individual Herd Results over Time. J Veterinar Sci Technol 5: 182. doi:10.4172/21577579.1000182

Johne's disease associated with implementation of a disease control program in Minnesota demonstration herds. See comment in PubMed Commons below J Dairy Sci 95: 4141-4152.

41. Nielsen SS, Toft $N$ (2009) A review of prevalences of paratuberculosis in farmed animals in Europe. See comment in PubMed Commons below Prev Vet Med 88: $1-14$

42. Olde Riekerink RG, Barkema HW, Veenstra S, Poole DE, Dingwell RT, et al. (2006) Prevalence of contagious mastitis pathogens in bulk tank milk in Prince Edward Island. See comment in PubMed Commons below Can Vet J 47: 567572 .
43. USDA, National Animal Health Monitoring System (2007) Dairy 2007: US Department of Agriculture, Animal and Plant Health Inspection Service Veterinary Services, National Animal Health Monitoring System.

44. Renshaw RW, Ray R, Dubovi EJ (2000) Comparison of virus isolation and reverse transcription polymerase chain reaction assay for detection of bovine viral diarrhea virus in bulk milk tank samples. J Vet Diagn Invest 12: 184-186.

45. Drew TW, Yapp F, Paton DJ (1999) The detection of bovine viral diarrhoea virus in bulk milk samples by the use of a single-tube RT-PCR. See comment in PubMed Commons below Vet Microbiol 64: 145-154. 